\title{
The self-selected use of social media for the pre-registration student nurse journey: An interpretative phenomenological analysis
}

\author{
Melanie Hayward* \\ Institue for Health and Social Care, Buckinghamshire New University, High Wycombe, England, UK
}

Received: July 23, 2021

DOI: $10.5430 /$ jnep.v12n2p59

\author{
Accepted: September 21, 2021 \\ Online Published: October 18, 2021 \\ URL: https://doi.org/10.5430/jnep.v12n2p59
}

\begin{abstract}
Objective: To explore the lived experience of the phenomenon of self-selected social media use through the viewpoint of UK pre-registered student nurses in relation to their studies.

Methods: Seven UK pre-registration student nurses who used social media in relation to their nursing studies were interviewed during February and March 2020. Semi-structured interviews were transcribed and analysed using interpretative phenomenological analysis.

Results: Four themes indicated that students used social media to discover, create and control their 'own space' for personal and professional benefit, through a 'whole new world' of social connections, 'opening doors' for learning and development to support themselves and each other on their 'journey to be nurses'. The analysis also revealed an inherent journey of self-discovery affording self-empowerment and resilience, the significance of which was dependent on each participant's characteristics and experiences.

Conclusions: Social media use may have the potential to assist student nurse decisions related to, enhance the experience of, and engagement in, their education. As an international phenomenon, social media could be considered as an agent to improve student nurse retention and facilitate recruitment. Future research is recommended to explore the use of social media in this way as well as the challenges to its use.
\end{abstract}

Key Words: Interpretative phenomenology, Social media, Nurse education, Nursing, Pre-registration student nurse, Retention

\section{INTRODUCTION}

The WHO (2016) promotes the integration of digital technology in nursing curricula globally. ${ }^{[1]}$ In the UK the most recent NMC $(2018 \mathrm{a})^{[2]}$ standards outline the necessity of integrating digital capability in pre-registration education to equip the qualified nurse for modern complex healthcare. ${ }^{[3,4]}$ Social media (SoMe) utilises digital technology to engage in networking and socialising activity through the creation and sharing of textual or pictorial information. ${ }^{[5]}$ The popularisa- tion and swift progress of SoMe means its use is widespread amongst university students worldwide, progressively using it to support their education. Yet, irrespective of its popularity, minimal qualitative studies examine the lived experience of student nurses (StNs), more specifically its self-chosen use in relation to their studies, outside of curricula. Evaluation of this phenomenon will promote a student StN-centric dialogue to support nurse educators to understand purpose and benefit from their perspective.

\footnotetext{
*Correspondence: Melanie Hayward; Email: melanie.hayward@bucks.ac.uk; Address: Institute for Health and Social Care, Buckinghamshire New University, High Wycombe Campus, Queen Alexandra Rd, High Wycombe, Buckinghamshire, HP11 2JZ, UK.
} 


\section{Background}

International evidence of SoMe use within healthcare education highlights a combination of research methodology. Literature reviews scrutinise limited pre-registration nursing studies compared to other disciplines but do offer some valuable insight. Chan and Leung's $(2018)^{[6]}$ review highlights Facebook and Twitter as the most favourable platforms, and although not suited to all learners, Petty $(2013)^{[7]}$ asserts SoMe is positively associated with user satisfaction. According to Gunberg Ross and Myers (2017), ${ }^{[8]}$ scholarly practice seemly role models appropriate student use and StNs are more likely to engage if it is a programme requirement. ${ }^{[9]}$ Ramage and Moorley's (2019) ${ }^{[10]}$ review supports some of these findings adding that being mostly aware of the professionality requirements, students primarily use SoMe to connect with peers and access pertinent information. A systematic review by O'Connor et al. (2018) ${ }^{[11]}$ analysing SoMe use solely in nursing and midwifery education, also reports discussion and information exchange, claiming benefits of knowledge and skills attainment.

Globally, research specific to pre-registration nursing students and their education is primarily mixed methods, mostly exploring StNs and lecturer's experiences following primarily academic-led or curricula-imposed activities using SoMe. Although very few studies show measurable benefits in educational outcomes, most studies do support its use in nursing courses to aid both personal and professional development. In line with Chan and Leung's (2018) ${ }^{[6]}$ broader healthcare review, the $\mathrm{StN}$ research also principally points to Facebook and Twitter as being most conducive, supporting the sharing of knowledge, experience and feelings along with making connections. ${ }^{[12-15]}$ Additionally, online learning through discussion and reflection, the promotion of critical thinking and the development of e-professionalism are observed. ${ }^{[16-18]}$ WhatsApp is also recognised as being advantageous for individual and group messaging, sharing information between peers, educators and nurses in practice. ${ }^{[19]}$ Morley $(2014)^{[20]}$ and Ryan and Davies (2016) ${ }^{[21]}$ UK studies discuss SoMe use for general and pastoral support, but most papers state that the connection with others, and their knowledge, assist a sense of belongingness and professional identity encouraging self-confidence to benefit a supportive culture.

This previous research primarily uses theoretical framing from a constructivist and connectivist viewpoint; community of practice frameworks and social capital models being the most common. Social capital, ${ }^{[22]}$ refers to the positive collaborative features and drivers of supportive social networks. Key notions such as bonding, bridging and linking help to understand its interpersonal, cognitive and organisational features. ${ }^{[23]}$ Wenger $(2010)^{[24]}$ communities of practice are related to social capital, asserting that the structure of SoMe affords valuable communal outcomes. StNs, academics and nursing experts can be virtually connected, supporting each other, advancing knowledge and practice together. ${ }^{[25,26]}$

Since 2017, SoMe accounts run by StNs for StNs have emerged, the most popular being @WeStudentNurses and the @StNurseProject. They have created a dedicated space for the sharing of knowledge, resources, and experiences, creating collective benefit for StNs. Current practice indicates that StNs, increasingly aware of this, are self-choosing to use SoMe to support their studies outside academic pedagogical endeavours of its use. It could be argued then that a paradigm shift is occurring, from primarily educative led SoMe use, to StNs now creating their own online communities and connections to support their education. This engagement type, evidenced through its sustainability and popularity, appears to be valued by StNs but is underexplored. This gap is therefore the focus of this research.

\section{METHODS}

\subsection{Aims}

To explore the lived experiences of UK pre-registration StNs utilising social media in relation to their studies. The focus was to understand the 'how' and 'why' of its use, that is to discover the purpose of self-selection, motivation for its ongoing use, and consequently its meaning and impact.

\subsection{Design}

The study adopted a subjective stance and an interpretative theoretical perspective. Smith et al. (2009) ${ }^{[27]}$ qualitative interpretative phenomenological analysis (IPA) methodology was consequently used as it supports researchers to gain a comprehensive understanding of a phenomenon through the examination and interpretation of individual participants making sense of their own experience. Being an academic within the university where the participants study, as well as the creator and curator of nurse programme SoMe accounts, it was vital to select an approach that acknowledged and valued researcher perception, such as IPA which employs double hermeneutics. Previously IPA has been used to explore university student well-being related to SoMe use ${ }^{[28]}$ as well as patient experience ${ }^{[29]}$ but at the time of this study's proposal, a published paper using IPA exploring this particular focus, with StNs had not been discovered.

\subsection{Participants}

This study utilised a purposive sampling technique; StNs studying at the same place of work as the researcher, using SoMe in relation to their nursing studies. In IPA, participants should share common experiences, and in turn 'represent a 
perspective' rather than a population. ${ }^{[27]}$ From this viewpoint, relationships, understandings, feelings, and other meaning can be interpreted. An inclusion and exclusion criteria were used to support homogeneity (see Table 1).

Being the most used platforms, and the most conducive way to collect a valid sample, participants were identified via a call for interest through the researcher's professional Twitter and Facebook accounts. Responses were followed up via direct message and/or email, dependent on whether the inclusion criteria were met. Smith et al. (2009) ${ }^{[27]}$ IPA supports a small sample to facilitate the individual lived experience to be explored in-depth, hence saturation is superfluous. Recruits $(\mathrm{N}=7)$ were StNs from all three fields of nursing taught: Child; Adult and Mental Health, across all year groups (see Table 2). One additional StN showed an interest in participating but later declined due to personal reasons.

Table 1. Inclusion and exclusion criteria used for the study's participant sample

\begin{tabular}{|l|l|}
\hline Inclusion Criteria & Exclusion Criteria \\
\hline $\begin{array}{l}\text { Pre-Registered StNs who use SoMe to support their nursing } \\
\text { studies. }\end{array}$ & $\begin{array}{l}\text { Pre-Registered StNs who do not use SoMe to support their } \\
\text { nursing studies. }\end{array}$ \\
$\begin{array}{ll}\text { - Studying any Pre-Registered Nursing programme; BSc Hons } \\
\text { (Fee-paying and apprenticeship) and PG Dip. }\end{array}$ & $\begin{array}{l}\text { - Post-registration StNs. } \\
\text { - All years of Pre-Registered Nursing study. }\end{array}$ \\
$\begin{array}{ll}\text { - Studying at the university where the researcher is employed. } \\
\end{array}$ & $\begin{array}{l}\text { Pre-Registered Nurses. } \\
\text { istemployed. }\end{array}$ \\
& courses. \\
\hline
\end{tabular}

\subsection{Data collection}

To generate rich data, a flexible reflexive discourse was created using individual face-to-face semi-structured interviews. Descriptive demographical data (see Table 2) were gathered at the start of each interview in case of influence on the experienced phenomena that may have proved valuable during analysis. Its collection also supported the building of researcher-participant rapport.

Table 2. Participant demographical information $(\mathrm{N}=7)$

\begin{tabular}{|c|c|c|c|c|c|c|c|}
\hline Pseudonyms & Claire & Sophia & Kajal & Thea & Haidar & Orzah & Mia \\
\hline $\begin{array}{l}\text { Year or stage of } \\
\text { study }\end{array}$ & 1 & 3 & 1 & 3 & 3 & 3 & 2 \\
\hline $\begin{array}{l}\text { Field of Nursing } \\
\text { studied }\end{array}$ & Adult & Adult & $\begin{array}{l}\text { Mental } \\
\text { Health }\end{array}$ & Child & Adult & Child & Adult \\
\hline Gender & Female & Female & Female & Female & Male & Female & Female \\
\hline Age & $45-49$ years & 25-29 years & $\begin{array}{l}18-24 \\
\text { years }\end{array}$ & 40-44 years & 30-34 years & 25-29 years & 25-29 years \\
\hline Ethnicity & $\begin{array}{l}\text { White } \\
\text { English }\end{array}$ & $\begin{array}{l}\text { White } \\
\text { British }\end{array}$ & $\begin{array}{l}\text { Mixed } \\
\text { White } \\
\text { Asian }\end{array}$ & $\begin{array}{l}\text { White } \\
\text { British }\end{array}$ & Black African & Asian other & White British \\
\hline $\begin{array}{l}\text { Length of time } \\
\text { using social media }\end{array}$ & $\begin{array}{l}\text { Less than } 6 \\
\text { Months }\end{array}$ & $11 / 2-2$ years & $\begin{array}{l}\text { Less than } \\
6 \text { months }\end{array}$ & $2-3$ years & $2-3$ years & $2-3$ years & $11 / 2-2$ years \\
\hline $\begin{array}{l}\text { Social media use } \\
\text { (approx. hrs./wk.) }\end{array}$ & 5-6 hours & 15-20 hours & 10 hours & 2 hours & 1 hour & 8 hours & 14 hours \\
\hline $\begin{array}{l}\text { Social media sites } \\
\text { used }\end{array}$ & $\begin{array}{l}\text { Twitter } \\
\text { YouTube }\end{array}$ & $\begin{array}{l}\text { Twitter } \\
\text { LinkedIn } \\
\text { Facebook } \\
\text { Instagram }\end{array}$ & Twitter & $\begin{array}{l}\text { Twitter } \\
\text { Facebook }\end{array}$ & $\begin{array}{l}\text { Twitter } \\
\text { WhatsApp } \\
\text { Facebook }\end{array}$ & $\begin{array}{l}\text { Twitter } \\
\text { WhatsApp } \\
\text { Snapchat } \\
\text { Facebook }\end{array}$ & $\begin{array}{l}\text { Twitter } \\
\text { WhatsApp } \\
\text { Facebook }\end{array}$ \\
\hline
\end{tabular}

Note. All the StNs used at least one SoMe platform. Twitter was the preferred site for all, and most discussed. Haidar, Orzar and Mia identified WhatsApp as being collaboratively beneficial, and Claire YouTube as educational. Other platforms were briefly mentioned, as indicated above, but none deemed advantageous for nursing studies.

A schedule of inductive open questions was utilised with additional prompts to explore further and seek clarification. This, alongside a broad opening question, and additional questions being asked on the day based on the interviewee's commentary, assured the process was participant-led. This is imperative in IPA as subjective meaning is desired (see 


\section{Appendix A).}

Interviews were arranged on a date and time suitable for the participant and took place in a private student study room at the university, during February and March 2020, in the presence of the researcher only. The average interview length was 45 minutes, each audio-recorded and subsequently transcribed verbatim. Individually, data sets were rechecked against the files and any errors changed or omissions added to ensure accuracy.

\subsection{Ethical considerations}

Ethical approval was obtained from the University's Research Ethics Committee. Consent was gained from the Head of School; primary gatekeeper, and SoMe terms of use were examined to ensure compliant recruitment. Before agreeing to involvement, respondents were given verbal and written information via a participation information sheet. Confirmation of an informed decision and subsequent consent was collected through a signed and dated form. To minimise researcher-participant power imbalance, recruitment via SoMe provided distance, and for those that responded positively, each was reassured that their participation was voluntary. Furthermore, a student space, as opposed to an academic office or classroom, was used to undertake all interviews. Interviewees were informed at all stages of their right to refuse to take part or to withdraw without consequence. All were also briefed of their right to decline to answer questions and/or end the interview at any point, as well as ask questions. To support anonymity, once recruited, participants were not contacted by the researcher via SoMe. To reduce bias, they were asked to refrain from posting regarding their experience. Audio recordings once downloaded and checked, were deleted from recording devices and remaining data stored on the researcher's computer as per university policy. Participant identity was protected through personally identifiable information remaining confidential; through pseudonyms, and recordings and documentation being encrypted.

\subsection{Data analysis}

Scrutiny of the data commenced at collection via researcher memos recording a contemporaneous reflexive summary of the content, feel and observations of each interview. Following interview completion, Smith et al. (2009) ${ }^{[27]}$ systematic design was followed (see Table 3).

Table 3. Data analysis design

\begin{tabular}{|l|}
\hline Refamiliarization of the data \\
- Multiple reading of the transcript and listening to the audio recording. \\
\hline - Descriptive, identifying explanations and key phrases \\
- Linguistic, focusing on how language was used, and \\
- Conceptual, questioning and perceiving the meaning of what was said \\
\hline Interpretative noting \\
- Observations made through further researcher reflexivity \\
- In-vivo coding used to retain notional minutiae within the participants' responses \\
\hline Multidirectional modifications \\
- Re-review and deconstruction \\
\hline Developing emergent themes \\
- Creation of phrases that captured the interviewees' original words and connotation alongside researcher interpretation \\
\hline Connecting themes \\
- Formed between using abstraction, subsumption, numeration and function \\
- New conjunctions labelled to create preliminary superordinate and subordinate themes \\
\hline
\end{tabular}

These steps were repeated by the sole researcher for each data set making every effort to bracket the ideas arisen from the previous to support idiography. Once completed, patterns across the cases were identified through the recognition of shared high order concepts which formed the ultimate superordinate themes, and idiosyncratic elements which were moulded into categories to form subordinates.

\subsection{Rigour}

Elliott, Fischer and Rennie's (1999) ${ }^{[30]}$ guidelines were observed alongside common philosophies of trustworthiness to support quality and promote rigour. ${ }^{[31]}$ Examples include relistening to the interviews and using peer debriefing and validation to support dependability and confirmability. As advised by Smith et al. (2009) member-checking was not 
employed to avoid the risk of undermining the interpretative role of the researcher. ${ }^{[27]}$ An academic colleague piloted the interview questions to assist technique refinement and schedule modification. Engaging participants in detailed interviews facilitated iterative examination ensuring an indepth exploration of the topic. The number of participants provided multiple data sources to support the development of a comprehensive interpretation of the phenomena. The researcher's supervisor reviewed two of the interview transcriptions to appraise the analytical process. To ensure alignment with the research question and subsequent authenticity, the themes and categories were presented to doctorate level scholars. These activities also supported the researcher to consider their position, instigating bracketing conversations to aid validity. A journal supported personal, epistemological, and critical reflexivity to decrease the risk of misconception or misinterpretation of the data. Finally, the reporting of this research has incorporated key principles set out in the Consolidated Criteria for Reporting Qualitative Research (COREQ) ${ }^{[32]}$ and Standards for Reporting Qualitative Research $(\mathrm{SRQR})^{[33]}$ specifications.

\section{ReSUlts}

Four superordinate themes were discovered. All were identified by each interviewee, but personal characteristics and experience meant certain themes were more significant to some individuals realities than others. Many associated subordinate themes and categories were identified but these were restricted to the most prominent or those with the richest data (see Table 4).

Table 4. Identified superordinate themes and subordinate themes

\begin{tabular}{|c|c|c|}
\hline & Superordinate Themes & Subordinate themes \\
\hline 1. & $\begin{array}{l}\text { A 'whole new world' of building personal and professional } \\
\text { connections }\end{array}$ & $\begin{array}{l}\text { - Community } \\
\text { - Communication } \\
\text { - Networking }\end{array}$ \\
\hline 2. & 'Opening doors' for improvement and growth & $\begin{array}{l}\text { - Academic work and practice learning } \\
\text { - Future progression and success }\end{array}$ \\
\hline 3. & Creation and control of 'own space' & $\begin{array}{l}\text { - Access and use of social media } \\
\text { - Personal value and professional benefit }\end{array}$ \\
\hline 4. & Supporting self and others 'on the journey to be nurses' & $\begin{array}{l}\text { - Developing 'the student nurse voice' } \\
\text { - 'Reaching out' to other student nurses } \\
\text { - Self-empowerment and resilience }\end{array}$ \\
\hline
\end{tabular}

3.1 Superordinate Theme 1: A 'whole new world' of building personal and professional connections

All participants discussed the connective benefits of SoMe. For some, this was especially impactful, and as aptly described by Claire, Kajal, Thea and Haidar, these connections "opened their eyes" to how social media could be used professionally within a "whole new world" of student and nurse communities of which they were previously unaware.

\subsubsection{Community - resolving the personal 'silo'}

One key reason for continued SoMe use was the sense of belonging to an understanding community. Feeling isolated from similar others was commonly expressed, and as indicated by the word 'just', perceived as being disadvantageous:

"well, you are just in a bit of a silo, aren't you?"

(Claire).

There was the need to connect with others to appreciate experiences, decisions, feelings and even the discipline itself to understand the wider context of student and professional existence. This was interpreted as a need to support selfassurance and self-identity. Sophia described that she felt

Published by Sciedu Press more understood and therefore accepted inside the StN and nurse SoMe community, than by her peers and other professionals outside it, such as those at university or on placement. The use of the phrase "shot down" suggested a feeling of rejection:

"I got a different reaction on there ... my ideas weren't being shot down... the more relatable it felt, the more I felt comfortable".

\subsubsection{Communication - 'the conversation starter and con- tinuer'}

All participants used SoMe as a communication tool; direct messaging, questioning, exchanging information, discussion. The sense of community was heightened for those who spent more time on SoMe, but mostly for those who engaged in dynamic interaction. It seemed that StNs who found it more challenging to be connected to or understood in their nonvirtual social world, posted most in the virtual.

“... it's about sharing with people... it is a conversation starter and continuer... with people 
... you ... don't even know, you get to know, or you already know”. (Mia).

Sophia, the most experienced and prevalent user, actively created or controlled conversation on Twitter posting for others and self-benefit. The word 'productive' is found six times in the transcript reflecting a desire for meaningful use:

"I probe to ... generate productive conversation. If someone said something quite basic, I will say 'explain that in more detail' I ... try to interact with a tweet in the way that [is] the purpose of Twitter ... to create a conversation".

In contrast, 1st year Kajal found the most useful conversations aided personal decision-making:

"I'm... looking at second and third years ... they ... answer with hindsight and knowledge... but equally lecturers ... give a professional point of view. I can merge the ... advice".

Those less certain in using SoMe or perceived to not be so reliant on virtual connections, profited from observing. $\mathrm{Ob}$ servation supported comparison or determining information to support personal goals encouraging self-confidence.

\subsection{3 'The Networking tool'}

The development and maintenance of peer, as well as disciplinary networks, was described by all, but the recognition of SoMe as a professional networking tool, by only those who had a more established StN identity. For Haidar, the initial drive for Twitter use was to connect with often inaccessible nursing experts. He excitedly recollected a conversation he had had with a peer:

“... 'we must develop our networking skills'. I think that is the main thing! ... 'we can reach any level we really want to in nursing!'”.

For others, it was perceived to be the increased belonging to communities, and the progressively meaningful connections within them, that provided self-confidence to identify Twitter in this way:

"it's just developed ... now it seems to be like a networking tool for me... if you follow the right people on Twitter ... you kind of get noticed" (Mia).

Others appreciated the benefit of the flattened hierarchy; being able to share their experience and concerns with those who have the power to make change, which in turn boosted confidence.

\subsection{Superordinate Theme 2: 'Opening doors' for im- provement and growth}

Several participants used the metaphor of "opening doors" supporting a sense of discovery of developmental and career opportunities.

\subsubsection{Academic work and practice learning - 'the hard- core information' and 'the headlines'}

Keeping up to date through Twitter was a dominant thread, recognised as conveniently supporting the continuous distribution of useful information signposts.

"I've seen this headline now I can go and look for what I'm looking for" (Mia).

This varied information appeared to be particularly useful for StNs who had a conscientious need to be well informed or were less confident to access professional literature. For some there was a sense of being in control, by being upto-date, this led to a sense of power which led to personal confidence.

All StNs found, as Claire described, "the sort of hardcore information useful" but the 3rd year StNs were the most likely to use SoMe to facilitate academic learning.

"they're putting out information that might seem complicated, but they're simplifying it... and explaining it at a level that's easier ... to understand" (Sophia).

Accessibility and intelligibility seemed to be primary reasons for ongoing engagement with Twitter in this way, supporting knowing where else to go to access additional sources. WhatsApp was also described as being useful for sharing links to articles or notes. For some, these elements may also be about reducing or avoiding the literature searching process, which in the short term seemed to create a sense of self-achievement.

Placement learning was also discussed. For example, access to patient stories enabled an understanding of patient perspective and this combined with the professional view appeared to support an understanding of practice complexity facilitating reflective learning.

\subsubsection{Future progression and success - 'taking myself out of my comfort zone; shaping where I want to go'}

Some StNs recognised being afforded professional development opportunities, which otherwise may have remained unexplored. Several participants also explained SoMe provided additional insight, supporting reflection of progression and the consideration of career goals. Sophia was particularly enthused during this section of the interview, the use of hand gestures and the word 'exciting' emphasised its importance: ISSN 1925-4040 E-ISSN 1925-4059 
"it's just constantly opening doors and giving me more choice.... it's been quite exciting ... I've kind of taken myself outside my comfort zone of what I know".

The use of the phrase "outside my comfort zone" indicated an understanding of purpose being tested, resulting in an enhanced level of focus, and there was a sense of an unexpected motivation. Mia as a 2 nd year also expressed similar benefits:

"it's really shaping where I want to go... it is giving me ideas and telling me things I didn't even know about".

Some StNs also discussed how SoMe facilitated the discovery and acquisition of job opportunities.

\subsection{Superordinate Theme 3: Creation and control of 'own space'}

StNs acknowledged that SoMe use had inherent decisions and associated challenges. Managing these, they shaped their use and involvement. This supported the formation of a unique online, and for some, offline "space" for individual benefit.

\subsubsection{Access and use of social media - 'popping on' and avoiding the 'rabbit hole'}

StNs who used WhatsApp recognised it to be for targeted communication, fittingly defined by Mia as "burst conversation", unlike Twitter which is the "place for ongoing discussion and connection". Participants reported following similar types of accounts: StNs, professional organisations, university, NHS Trusts and services, experts in the field. During initial use, these choices appeared to relate to reaffirming self-identity; personal, student and professional. As SoMe use progressed most StNs tailored their feeds according to individual need and perceived benefit:

"it's creating your own space... if a student nurse... talking about leadership or they've gone to a conference... I find that's a good one to follow... to see others motivated about things, even if I just scroll past ... it's still going to create the atmosphere that's gonna motivate me" (Sophia).

Three other participants recognised Twitter as customisable, using the phrase "created own space". As well as motivational value, it provided a sense of security, supporting control, boosting contribution and self-confidence.

Published by Sciedu Press
StNs almost exclusively accessed SoMe through their smartphone. This continued accessibility led to habitual use in response to specific situations:

“... when I'm having a cup of tea, waiting for a train, when I'm on a little downtime at work... you can pop in and out ... there is always something happening" (Sophia).

The phrase "pop in and out" used by three interviewees, implied entering and exiting the platform briefly, choosing to take part or not. This seems like a fear of missing out but was perceived as important to maintain a connection with the accepted community. For some, SoMe was used to put off the inevitable by convincing self it was positive:

"it's quite useful if you're a procrastinator to think you're doing something useful ... and it's going on Twitter, which is obviously nursing stuff ..., but you know, can easily lead you down a rabbit hole into something" (Claire).

\subsubsection{Personal value and professional benefit - Having a} 'key to the backroom' but 'being mindful' once there

Some StNs attained advantage through active management, developing skills of self-regulation and self-control. These interviewees were often more purposeful in their usage, focused on self-development. StNs who did not discuss this were more focused on developing relationships and supporting others. Activities included: time limits, restricting follow-ship, muting notifications. A benefit of proactively personalising SoMe use was to aid decision making through observation and reflection related to 'outside space'. This was described by some of the participants mostly in relation to career, university, and employment decisions.

"you can sort of investigate all the different places you could go to study... how active they were on Twitter was important, because, every sort of engagement ... makes you feel more confident about the choices you're making... it's like a key to the backroom... you can get a bit more of a sense of what a place is like and what to expect ..." (Claire).

In this, and other examples, it was perceived that StNs felt a Twitter presence meant an open and welcoming culture, and as intimated by Claire's use of the metaphor "key to the backroom" this was an indirect, but powerful way of understanding this.

Due to the meaning attached to Twitter accounts and StN observations of other's contributions to their feeds, participants were aware of the importance of controlling theirs, 
demonstrating a developing professional consciousness. Mia used the phrase "being mindful" eight times indicating underlining anxiety, which was shared but motivated all to reflect and practice e-professionalism:

"Twitter definitely helps with the kind of confidentiality side of things ... just double thinking before I hit send" (Kajal).

\subsection{Superordinate Theme 4: Supporting self and others 'on the journey to be nurses'}

All participants referred to the StN experience as a "journey", self-recognising or distinguishing in others the personal effort required. They all spoke of the importance of supporting similar others, and either consciously or unconsciously assisting themselves.

\subsubsection{Developing the 'student nurse voice'}

SoMe was central to facilitating the student voice for personal recognition or community-focused like-minded change, accordingly, developing professional confidence. All the participants apart from Claire discussed this. Mia described that being able to "... look, watch, think..." within SoMe's different spaces or communities unnoticed, supported an understanding of where she fitted and where her contributions would be welcomed and valued:

"You kind of find out where you have a voice and can say something interesting, important, and no one's gonna shout at me for it".

For Kajal and Thea the freedom and support to use their voice held significant value evidenced by the repeated nature it is discussed. Kajal states nine times that Twitter is used to "document my successes" and Thea six times "to blow my own trumpet". For them there is a sense that this is not about being heard per se but about exercising self-determination; having some control where often, due to "personal barriers" it is lacking, permitting themselves to feel proud. For Haidar, the value was in being heard, self-confirming that content shared has worth, supporting self-confidence:

"using Twitter will really make my voice... heard ... most of the people I follow ... are in [the] healthcare sector ... I have the appropriate people that will be interested in what I'm writing".

The 'student voice' was as much about the communal as it was about the individual and sometimes would activate change talk. Mia gave an example regarding the of lack empathy demonstrated by some qualified nurses in practice: 66
'It's like they've forgotten what it's like to be a student. .. they're like, 'Oh, just get on with it. It's going to be stressful'... but then we discuss ways to cope ...".

\subsection{2 'Reaching out' to other student nurses - 'making a difference'}

By stating "reaching out" 11 times, Haidar spoke of the drive to use SoMe to benefit others and self. Like others, selfexperience was the key motivator:

“... some people have made ... a positive change in my life through Twitter... maybe my opinion will be useful to someone else".

All StNs described being interested in and caring for others via SoMe providing words of support, brief advice or even challenge, but both Mia and Sophia articulated peer-empathy, detailing much of their activity as pro-social behaviour "making a difference".

'I'm invested in other students' journeys ... [I post] a lot about issues that affected me or other[s]... I've also had them reach out to me, [they] need to speak to someone... even if it's just two or three students I've helped create a better student experience for, that's great!" (Sophia).

Much of the discussion about supporting others felt like the engagement of self-talk. There was a sense of self-reflection and coincidingly reassuring themselves to enhance their own journey, consequently leading to self-empowerment. Kaja, who used the word "journey" concerning her own, and other StNs experiences 15 times claimed to be a "cheerleader for other people's successes" but also appeared to be supporting self:

"You're doing it! You're getting it! ... you're doing well! ... I just keep reminding people, reminding myself, of why we're on the journey to be nurses".

\subsubsection{Self-empowerment and resilience - 'finding my feet' and 'getting back on track'}

The strengthening of relationships through SoMe connection provided valued emotional support for most participants. But just as StNs reached out to peers to offer support for their journey, many reached out to the community for their own:

"It hit me in 2nd year. . you're in this weird middle place, you need emotional support, if it's not

ISSN 1925-4040 E-ISSN 1925-4059 
around you, you will crash. Twitter ...it's filled that gap. It doesn't shut down for an hour at night or anything. It's constant. You can kind of get that support, for yourself, you can just kind of reach out" (Mia).

This, alongside the knowledge and skills they developed, and the opportunities afforded them, supported selfempowerment and the development of resilience as implied by the metaphors "finding my feet" and "getting back on track" here:

"I've found a supportive community... I think I would be a less confident person in terms of my nursing journey. I'm grateful that it... exists it's definitely helped me to find my feet when I've been knocked off" (Kajal).

"It's sort of gotten me back on track with focusing on... and my motivation in my degree... I'm very reliant on the support network... [its] kept me going... [I'm] really grateful for having found it because, you know, I'm not sure I would still be on the degree without it" (Sophia).

\section{Discussion}

This study aimed to explore, in-depth, the experiences of StNs who self-select to use SoMe in relation to their studies. The findings outline important themes related to purpose and motivation, and accordingly its meaning and impact; connection with others, opportunities for improvement and growth, creating and controlling online and offline space and ongoing support. Signifying both personal and professional value, SoMe conveniently promotes social linking and bonding via passive, ad hoc or proactive engagement, promoting individual and communal benefits of belongingness, enhancing knowledge, developing skills, and fostering wellbeing. Even though most of the existing literature evaluates the pedagogic use of SoMe with StNs, it also emphasises much of these findings and hence these conclusions support the previous empirical evidence and theoretical foundations. ${ }^{[6,12-21]}$ While these features justify further examination, to do so in any additional detail separately may lead to a failure to fully appreciate the perceived connectedness that this study has uniquely revealed.

The interpretation of each individual's story, the consequent themes and related concepts contribute to the understanding of the personal and professional journey of self-discovery for the StN. All participants had implicit or explicit expressed needs or desires related to their education that SoMe use assisted, such as being understood, accepted, known, supportive and supported, and to learn, succeed and be satisfied.

Published by Sciedu Press
As individuals with distinct characteristics and experiences, each was at a different stage of their journey, but used SoMe for similar reasons and in comparable ways, just with differing significance, in relation to their studies. Like many IPA studies, a sense of self is a central thread, with multiple 'selfs' being present in each superordinate theme, some being more dominant than others (see Appendix B).

This research shows that SoMe use promotes self-identity and self-assurance leading to belongingness through connection and sharing with others. These 'selfs' are developed further through opportunity for improvement and growth, the resulting knowledge and skills facilitating self-achievement, supporting self-confidence, and moving towards current or new goals. Self-regulation and decision making involved in SoMe use provide personal and professional benefits leading to and from the creation and control of own space, fostering self-motivation. Supporting others encourages selfreflection to understand their own experiences, as well as receive support from others, within the controlled space. Self-determination is reinforced and evidenced in some way through the student voice. Through all these elements, selfempowerment is established, and resilience built, for the StN to strengthen, develop and adapt, leading to the personal and professional self-discovery of purpose and potential to overcome the challenges of their journey and carry on.

The pre-registration $\mathrm{StN}$ journey is recognised for its numerous challenges, documented autobiographically, ${ }^{[34]}$ explored broadly as a transitional process ${ }^{[35]}$ and more specifically in terms of knowledge or skills development, ${ }^{[36,37]}$ but not explicitly through the lens of SoMe. General higher education (HE) literature examines student journeying as a way to understand and improve student experience, and few studies, such as Galan et al. (2015) ${ }^{[38]}$ exploration of post-graduate business students' decision-making, encompass the role of SoMe, examined primarily from a marketing, recruitment or retention perspective. Reasons for $\mathrm{StN}$ attrition are multiple and complex. HEE (2018a ${ }^{[39]}$ Reducing Pre-registration Attrition and Improving Retention (RePAIR) report like wider HE research, ${ }^{[40]}$ found placement experience, academic expectations, academic and practice support and certain transitional points to be crucial. Tinto (2006) ${ }^{[41]}$ seminal research states student challenge leading to attrition can primarily be overcome through improved integration to the learning environment and its community and as such, aspects of social capital are significant. Literature affirms that belongingness is central to student retention and nursing research such as Collard et al. (2020) ${ }^{[42]}$ states StNs also require opportunity to self-reflect, develop self-help behaviours, be empowered and build upon strengths, hence resilience. 
The participants in this study discuss many attrition risks and describe how SoMe has supported them with these elements of their studies. The interpretation of their experiences identified many protective factors. Consequently, this research cautiously suggests that as a socialisation tool, SoMe has the potential to enhance StN experience and engagement and be an agent to improve retention through connectivity and community, providing support, information, activities, online discussion, and networking opportunities. A central reason for this appears to be that SoMe affords instantaneous and straightforward connection with, and timely responses from, similar others negating any significant effort to seek out confidants or negotiate systems or processes to access support or information. It is important to note though, that this type of activity does pose a risk of being misinformed, misunderstood, breaking professional codes, engaging in or being subject to cyber incivility. ${ }^{[43]}$ Some participants described being concerned about the possibility of being negatively targeted, but mainly about the importance of being mindful to engage in e-professionalism.

This research also proposes that active SoMe presence, beyond marketing efforts, may support StN recruitment. It is suggested that an inside perspective of university and programme culture is accessible to prospective StNs via what is shared, how it and its educators engage with existing StNs and how they engage with each other. As student recruitment and retention is a complex field, nursing education varies across the globe, and evidence demonstrates SoMe is not suited to all, variable engagement is expected, and SoMe would form just one element of a multi-faceted approach. ${ }^{[44]}$

The findings and recommendations are contextually significant. The current emphasis on nurses and StNs across the world to develop digital capability for an increasingly complex and technology-focused healthcare system exists within a global landscape of nursing shortages. ${ }^{[45]}$ This has been compounded by ongoing reduced StN enrolment, although lately seen a resurgence in some countries such as the UK due to COVID-19, ${ }^{[46]}$ as well as continued undiminishing attrition rates. ${ }^{[47]}$ This, alongside the international ${ }^{[45]}$ and recently renewed national focus on workforce growth and retention ${ }^{[48,49]}$ provides a beneficial impetus for the consideration and promotion of SoMe use.

\section{Limitations}

Participants were likely to engage with SoMe regularly, so opinions sought likely to be primarily positive. But this was an accepted singularity, as the study was not seeking to find out whether SoMe is a supportive tool, but rather the purpose and motivation for its use, and consequently its meaning and impact. Even so, there were noteworthy findings regarding challenges to SoMe use, such as concerns of cyber incivility, that have been omitted which require further exploration to support the recommendations.

Potential bias was reduced by not suggesting SoMe platforms for discussion. Using a definition provided via the participation sheet, interviewees identified for themselves which platforms they perceived as SoMe. But this may have led to an omission of useful data through some sites being used, but not discussed. Other mitigating actions against bias was undertaken, such as the avoidance of associated socially constructed metaphors and the choice of pseudonyms. ${ }^{[50]}$

Significantly, this study is placed within the interpretivist paradigm and consequently the connection with StN journeying through self-discovery, and the link made to retention and recruitment is just one understanding of self-chosen StN SoMe use. It is therefore acknowledged that this IPA study may not be generalisable outside the country, university, or discipline in which it is undertaken. Nonetheless, it does supplement the existing evidence and may have the potential to support further research to gain added insight into the phenomenon's possible benefit for prospective and current StN experience and HE outcomes.

\section{Conclusion}

While there is research that explores SoMe use within nurse curricula, this IPA study has uniquely explored the lived experiences of UK pre-registration StNs self-choosing to utilise social media in relation to their studies. The findings support the existing evidence, that SoMe aids users to participate in instantaneous online communal action with others, promoting multiple benefits for both personal and professional development. Critically, what this IPA study has originally revealed is why the phenomenon of StN self-selected SoMe use continues and is valued, in that it appears to support a journey of personal and professional self-discovery. The development of multiple 'self's' through the lens of SoMe assist decision making, facilitate self-empowerment and support resilience which ultimately help overcome challenges associated with the StN journey.

In line with IPA methodology, this study can only tentatively make broad recommendations for future practice in line with the subjective evaluation presented. Accordingly, it is cautiously suggested that as an international phenomenon, SoMe could be considered by nurse education globally, as a tool to aid recruitment, but predominantly the retention of StNs. Nursing faculty and healthcare organisations may want to use the findings to consider their SoMe presence, and academics as well as nurses, practice educators and conceivably healthcare managers their own usage. Importantly, 
StNs should be introduced to SoMe, primarily Twitter, as a personal and professional tool, alongside e-professionalism early on in their nursing education. This will facilitate the exploration of its potential benefits for their own StN journey and consequently inform their decisions regarding its use. Most significantly this study is purposeful in acting as a springboard for further research. An enhanced examination of StN experience could be undertaken with data from a wider sample such as including the learning disability field and post-graduate pre-registration StNs and/or a larger sample using an alternative study design. Future research should explore the validity of the overarching interpretive concept of the journey of StN self-discovery through the lens of SoMe, as well as the relationship between StN SoMe use and attrition rates. Centrally, a more in-depth understanding of why some StNs value SoMe so highly as a supportive tool in addition to, or possibly instead of, other services or professionals may enable faculty, wider student facilities and practice areas to appreciate the nuances of their journeys and

\section{REFERENCES}

[1] World Health Organisation. Nurse educator core competencies. Geneva: World Health Organisation; 2016.

[2] Nursing and Midwifery Council. Standards for nurses [Internet]. 2018 [cited 2021 Jan 2]. Available from: https : //www.nmc.org. uk/standards/standards-for-nurses/

[3] NHS England. NHS England Digital technology [Internet]. 2018 [cited 2019 Dec 16]. Available from: https ://www .england.nh s.uk/digitaltechnology/

[4] NHS England and NHS Improvement. The NHS Long Term Plan [Internet]. 2019 [cited 2020 Aug 19]. Available from: https://www. longtermplan.nhs.uk/wp-content/uploads /2019/08/nhs-long-term-plan-version-1.2.pdf

[5] Obar JA, Wildman S. Social media definition and the governance challenge: An introduction to the special issue. Telecommunications Policy. 2015; 39: 745-750. https://doi.org/10.1016/j.telp ol.2015.07.014

[6] Chan WS, Leung AY. Use of Social Network Sites for Communication Among Health Professionals: Systematic Review. J Med Internet Res. 2018; 20: e117. PMid:29592845 https ://doi .org/10.219 6/jmir. 8382

[7] Petty J. Interactive, technology-enhanced self-regulated learning tools in healthcare education: A literature review. Nurse Education Today. 2013; 33: 53-59. PMid:22818225 https://doi.org/10.1016/j. nedt. 2012.06.008

[8] Gunberg Ross J, Myers SMS. The Current Use of Social Media in Undergraduate Nursing Education: A Review of the Literature. CIN: Computers, Informatics, Nursing. 2017; 35: 338-344. PMid:28288034 https://doi.org/10.1097/CIN.0000000000 000342

[9] Webb L, Clough J, O'Reilly D, et al. The utility and impact of information communication technology (ICT) for pre-registration nurse education: A narrative synthesis systematic review. Nurse orientate their provision to be more StN centric. In addition, the challenges to SoMe use discussed by the participants, but not all examined in this study due to its focus, should be explored further.

SoMe has progressed considerably since its conception and is not diminishing. Now is the time for enhanced study in this area and to embrace its use further, for StN, university, wider $\mathrm{HE}$ and workforce advantage.

\section{ACKNOWLEDGEMENTS}

The author would like to thank her supervisor Dr Karen Harrison-White for all the guidance given throughout the research process. Also, to academic colleague's Dr Julia Williams and Ashley Luchmun who supported piloting, debriefing and validation. The biggest thanks go to the student nurses who shared their lived experience of social media use.

\section{CONFLicts OF InTEREST Disclosure}

The author declares that they have no competing interests.
Education Today. 2017; 48: 160-171. PMid:27816862 https: //doi.org/10.1016/j.nedt.2016.10.007

[10] Ramage C, Moorley C. A narrative synthesis on healthcare students use and understanding of social media: Implications for practice. Nurse Education Today. 2019; 77: 40-52. PMid:30954855 https://doi.org/10.1016/j.nedt.2019.03.010

[11] O'Connor S, Jolliffe S, Stanmore E, et al. Social media in nursing and midwifery education: A mixed study systematic review. Journal of Advanced Nursing. 2018; 74: 2273-2289. PMid:30019486 https://doi.org/10.1111/jan.13799

[12] Mistry V. Critical care training: using Twitter as a teaching tool British Journal of Nursing. 2011; 20: 1292-1296. PMid:22068003 https://doi.org/10.12968/bjon.2011.20.20.1292

[13] Garrett BM, Cutting R. Using social media to promote international student partnerships. Nurse Education in Practice. 2012; 12: 340-345. PMid:22595660 https://doi.org/10.1016/j.nepr. 2012.04 .003

[14] Sinclair W, McLoughlin M, Warne T. To Twitter to Woo: Harnessing the power of social media (SoMe) in nurse education to enhance the student's experience. Nurse Education in Practice. 2015; 15: 507-511. PMid:26119057 https://doi.org/10.1016/j .nepr.2015.06 .002

[15] Jackson J, Gettings S, Metcalfe A. "The power of Twitter": Using social media at a conference with nursing students. Nurse Education Today. 2018; 68: 188-192. PMid:29945099 https://doi.org/10 $.1016 / j$.nedt .2018 .06 .017

[16] Jones R, Kelsey J, Nelmes P, et al. Introducing Twitter as an assessed component of the undergraduate nursing curriculum: case study. J Adv Nurs. 2016; 72: 1638-1653. PMid:26861572 https: //doi.org/10.1111/jan.12935

[17] Richardson J, Grose J, Nelmes P, et al. Tweet if you want to be sustainable: a thematic analysis of a Twitter chat to discuss sustainability in 
nurse education. Journal of Advanced Nursing. 2016; 72: 1086-1096. PMid:26821875 https://doi.org/10.1111/jan.12900

[18] Price AM, Devis K, LeMoine G, et al. First year nursing students use of social media within education: Results of a survey. Nurse Education Today. 2018; 61: 70-76. PMid:29179050 https: //doi.org/10.1016/j.nedt.2017.10.013

[19] Lewis R, Kelly S. Changing hearts and minds: examining student nurses' experiences and perceptions of a general practice placement through a 'community of practice' lens. BMC Medical Education. 2018; 18: 67. PMid:29622005 https ://doi .org/10.1186/s129 09-018-1182-6

[20] Morley DA. Supporting student nurses in practice with additional online communication tools. Nurse Education in Practice. 2014; 14: 69-75. PMid:23871299 https ://doi.org/10.1016/j.nepr .2013 .06 .005

[21] Ryan GS, Davies F. Development and evaluation of an online, interactive information and advice tool for pre-registration nursing students. Nurse Education in Practice. 2016; 17: 214-222. PMid:26928823 https://doi.org/10.1016/j.nepr.2016.01.002

[22] Bourdieu P. The Forms of Capital. In: Richardson J, editor. Handbook of Theory and Research for the Sociology of Education [Internet] New York: Greenwood Press; 1986 [cited 2020 Feb 14]. p. 241-258 http://doi.wiley.com/10.1002/9780470755679.ch15

[23] Field J, Spence L. Informal learning and Social capital. In: Coffield F, editor. The Necessity of Informal Learning. Bristol: Policy Press; 2000. p. 32-42.

[24] Wenger E. Communities of practice and social learning systems: the career of a concept. In: Blackmore C, editor. Social learning systems and communities of practice [Internet]. London: Springer; 2010 [cited 2015 May 31]. p. 179-198. Available from: http://link.s pringer.com/chapter/10.1007/978-1-84996-133-2_11 ht tps://doi.org/10.1007/978-1-84996-133-2_11

[25] Wu TT. Using smart mobile devices in social-network-based health education practice: A learning behavior analysis. Nurse Education Today. 2014; 34: 958-963. PMid:24568697 https ://doi .org/10 $.1016 /$ j.nedt . 2014.01 .013

[26] Aasbrenn M, Raustøl A, Bingen HM. The internet and nurse education. Nurse Education in Practice. 2017; 26: A1-A3. PMid:28802671 https ://doi.org/10.1016/j.nepr.2017.08.010

[27] Smith JA, Flowers P, Larkin M. Interpretative phenomenological analysis: theory, method and research. Thousand Oaks: SAGE Publications; 2009.

[28] Gardiner-McGregor D. Social Media and Well-Being: An Interpretative Phenomenological Analysis Exploring Interpretations of Social Media, Perception of Self, and Well-Being Amongst University Students [Internet]. [Manchester]: Manchester Metropolitan University; 2019. Available from: http://e-space.mmu.ac.uk/623899/

[29] Peat GW. An Interpretative Phenomenological Analysis of the role of social media in the lives of young men with neuromuscular conditions [Internet] [phd]. University of Leeds; 2021 [cited 2021 Jun 6] Available from: https://etheses.whiterose.ac.uk/28810/

[30] Elliott R, Fischer CT, Rennie DL. Evolving guidelines for publication of qualitative research studies in psychology and related fields. British Journal of Clinical Psychology. 1999; 38: 215-229. PMid:10532145 https://doi.org/10.1348/014466599162782

[31] Lincoln YS, Lynham S, Guba EG. Paradigmatic controversies, contradictions, and emerging confluences. In: Denzin NK, Lincoln YS, editors. The Sage handbook of qualitative research. 5 th ed. Thousand Oaks: SAGE Publications; 2017. p. 108-151.

[32] Tong A, Sainsbury P, Craig J. Consolidated criteria for reporting qualitative research (COREQ): a 32-item checklist for interviews and focus groups. Int J Qual Health Care. 2007; 19: 349-357. PMid:17872937 https://doi.org/10.1093/intqhc/mzm042

[33] O'Brien BC, Harris IB, Beckman TJ, et al. Standards for Reporting Qualitative Research: A Synthesis of Recommendations. Academic Medicine. 2014; 89: 1245-1251. PMid:24979285 https: //doi.org/10.1097/ACM.0000000000000388

[34] Huscroft C. It can be nerve-wracking, but the journey from student to nurse is well worth it. Br J Nurs. 2020; 29: 713-713. PMid:32579467 https://doi.org/10.12968/bjon.2020.29.12.713

[35] Holland K. A journey to becoming: the student nurse in transition. Journal of Advanced Nursing. 1999; 29: 229-236. PMid:10064303 https://doi.org/10.1046/j.1365-2648.1999.00883.x

[36] Standing M. Clinical decision-making skills on the developmental journey from student to Registered Nurse: a longitudinal inquiry. Journal of Advanced Nursing. 2007; 60: 257-269.

[37] Walker S, Rossi D, Anastasi J, et al. Indicators of undergraduate nursing students' satisfaction with their learning journey: An integrative review. Nurse Education Today. 2016; 43: 40-48. PMid:27286943 https://doi.org/10.1016/j.nedt.2016.04.011

[38] Galan M, Lawley M, Clements M. Social media's use in postgraduate students' decision-making journey: an exploratory study. Journal of Marketing for Higher Education. 2015; 25: 287-312. https://doi.org/10.1080/08841241.2015.1083512

[39] Health Education England. RePAIR. Reducing Preregistration Attrition and Improving Retention Report [Internet]. 2018 [cited 2020 Aug 25]. Available from: https ://www.hee.nhs.uk/our-work/reducing-pre-r egistration-attrition-improving-retention

[40] Webb O, Wyness L, Cotton D. Enhancing access, retention, attainment and progression in higher education [Internet]. York: Higher Education Academy; 2017 [cited 2020 Aug 25]. Available from: https://www.heacademy.ac.uk/system/files/resou rces/enhancing_access_retention_attainment_and_pro gression_in_higher_education.pdf

[41] Tinto V. Research and Practice of Student Retention: What Next? Journal of College Student Retention: Research, Theory \& Practice. 2006; 8: 1-19. https://doi.org/10.2190/4YNU-4TMB-2 2DJ-AN4W

[42] Collard SS, Scammell J, Tee S. Closing the gap on nurse retention: A scoping review of implications for undergraduate education. Nurse Education Today. 2020; 84: 104253. PMid:31706205 https ://doi.org/10.1016/j.nedt.2019.104253

[43] De Gagne JC, Hall K, Conklin JL, et al. Uncovering cyberincivility among nurses and nursing students on Twitter: A data mining study. International Journal of Nursing Studies. 2019; 89: 24-31. PMid:30321747 https://doi.org/10.1016/j.ijnurstu. 201 8.09 .009

[44] Mooring QE. Recruitment, advising, and retention programs - Challenges and solutions to the international problem of poor nursing student retention: A narrative literature review. Nurse Education Today. 2016; 40: 204-208. PMid:27125174 https ://doi .org/10.1 016/j.nedt. 2016.03 .003

[45] World Health Organization. Nursing and midwifery [Internet]. 2020 [cited 2021 Jun 29]. Available from: https://www. who.int/ne ws-room/fact-sheets/detail/nursing-and-midwifery

[46] NHS England. 'Your NHS needs you' call attracts thousands more student nurses [Internet]. 2020 [cited 2020 Aug 30]. Available from: https ://www .england.nhs.uk/2020/08/your-nhs-needs -you-call-attracts-thousands-more-student-nurses /

[47] Buchan J, Charlesworth A, Gershlick B, et al. A critical moment: NHS staffing trends, retention and attrition [Internet]. London: The Health Foundation; 2019 [cited 2020 Aug 25]. Available from: 
https://www.health.org.uk/sites/default/files/uplo ad/publications/2019/A\%20Critical\%20Moment_1.pdf

[48] Health Education England. RePAIR. Reducing Preregistration Attrition and Improving Retention Toolkit [Internet]. 2018 [cited 2020 Aug 25]. Available from: https://www.hee.nhs.uk/our-work/reducing-pre-r egistration-attrition-improving-retention
[49] NHS England. We are the NHS: People Plan 2020/21 - action for us all [Internet]. 2020 [cited 2020 Aug 27]. Available from: https: //www.england.nhs.uk/wp-content/uploads/2020/07/We_ Are_The_NHS_Action_For_All_Of_Us_FINAL_24_08_20.pdf

[50] Dovidio J, Kawakami K, Gaertner S. Reducing Contemporary Prejudice: Combating Explicit and Implicit Bias. In: Oskamp S, editor. Reducing prejudice and discrimination. New Jersey: Lawrence Erlbaum Associates Publishers; 2000. p. 137-163. 